\title{
Genetic Diversity in Commercial Rapeseed (Brassica napus L.) Varieties from Turkey as Revealed by RAPD
}

\author{
Özlem ÖZBEK*, Betül Uçar GIDIK \\ Hitit University, Faculty of Arts and Sciences, Department of Biology, Ulukavak Mah. Ciftlik Cayiri \\ Cd.No:61, Çorum, Turkey; ozbekozlem@gmail.com (*corresponding author)
}

\begin{abstract}
In cultivated commercial crop species, genetic diversity tends to decrease because of the extensive breeding processes. Therefore, germplasm of commercial crop species, such as Brassica napus L. should be evaluated and the genotypes, which have higher genetic diversity index, should be addressed as potential parental cross materials in breeding programs. In this study, the genetic diversity was analysed by using randomly amplified polymorphic DNA analysis (RAPD) technique in nine Turkish commercial rapeseed varieties. The RAPD primers (10-mer oligonucleotides) produced 51 scorable loci, 31 loci of which were polymorphic (60.78\%) and 20 loci (39.22\%) were monomorphic The RAPD bands were scored as binary matrix data and were analysed using POPGENE version 1.32. At locus level, the values of genetic diversity within population $\left(H_{s}\right)$ and total $\left(H_{T}\right)$ were 0.15 and 0.19 respectively. The genetic differentiation $\left(G_{S T}\right)$ and the gene flow $\left(N_{m}\right)$ values between the populations were 0.20 and 2.05 respectively. The mean number of alleles $\left(n_{a}\right)$, the mean number of effective alleles $\left(n_{a e}\right)$, and the mean value of genetic diversity $\left(H_{e}\right)$ were $2.00,1.26$, and 0.19 respectively. According to Pearson's correlation, multiple regression and principal component analyses, eco-geographical conditions in combination had significant effect on genetic indices of commercial B. napus L. varieties were discussed.
\end{abstract}

Keywords: Brassica napus L. commercial varieties, canola, genetic variation, molecular markers, RAPD polymorphism, vegetable oilseed crop

\section{Introduction}

Brassica napus L. $(2 \mathrm{n}=38, A A C C)$ belongs to the genus Brassica L. (Brassicaceae). It is originated through spontaneous hybridisations between turnip rape $(B$. rapa L., $A A, 2 \mathrm{n}=20)$ and cabbage (B. oleracea L., $C C, 2 \mathrm{n}=18$ ) (Kimber and McGregor, 1995). It is the second important source of vegetable oilseed crop in the worldwide after soybean. Because of intensive breeding processes Brassica napus L. has a relatively narrow genetic diversity in current germplasm. The breeders manage plant material originating worldwide to increase the existing genetic diversity, which especially highlights its resistance to agricultural environments (change in climate, biological stress factors, which are new in the area, and market requirements) (Marjanovic et al., 2009).

A variety of molecular markers has been used to study the genetic variation among the diverse group of important crops in the genus Brassica, such as: Analysis of genetic diversity in the Brassica napus L. using SSR (Chen et al., 2009; Hasan et al., 2006; Qu et al., 2012); RAPD markers (Ahmad et al., 2007; Fazeli et al., 2008; Gečaitè et al., 2009; Marjanovic et al. 2009; Moghaddam et al., 2009; Nisar et al., 2007; Shiran et al., 2006); Characterisation of Brassica napus germplasm based on molecular markers (Shahid et al., 2011); Genetic diversity of Brassica napus L. varieties estimated by morphological and molecular markers (Fahmi et al., 2012).

The aim of this study is to analyse the genetic diversity among nine Turkish commercial rapeseed (Brassica napus L.) varieties. Analyses were made to estimate the following genetic parameters: Allele richness $(n)$, effective allele number $\left(n_{a e}\right)$, genetic diversity $\left(H_{\rho}\right)$, genetic diversity within $\left(H_{S}\right)$ and total $\left(H_{T}\right)$, genetic differentiation between populations $\left(G_{S T}\right)$. In addition, the effects of climate (temperature $T$, humidity $H$, wind $W$, and rainfall $R$ ) and geography (altitude $A L$, latitude $L T$, and longitude $L N)$ on the genetic diversity of five Turkish commercial rapeseed (Brassica napus L.) varieties according to RAPD markers.

\section{Materials and methods}

\section{Plant material}

In this study, nine different Turkish commercial rapeseed (Brassica napus L.) varieties (Tab. 1) were analysed genetically by using 10 RAPD primers, sequence of which were given in Tab. 2. The seeds of five varieties ('Licord', 'Elvis', 'Californium', 'PR46W31', and 'Tarcoola') were harvested from farmers' fields $\left(<1000 \mathrm{~m}^{2}\right)$, which are located at Trakya region of Turkey in August of 2010 by Betül Gıdık. Turkey branches of international companies 
Tab. 1. The locations, altitudes (AL), number of sample (N) and variety codes (PC) of the commercial rapeseed (Brassica napus L.) varieties used in this study

\begin{tabular}{|c|c|c|c|c|c|}
\hline & PC & Variety & Provinces/Companies & $\mathrm{N}$ & $\mathrm{AL}(\mathrm{m})$ \\
\hline \multirow{4}{*}{$\begin{array}{l}\text { Varieties provided by } \\
\text { commercial companies }\end{array}$} & A & 'NK Petrol' & SYNGENTA & 20 & \\
\hline & B & 'Tristan' & KWS & 20 & \\
\hline & $\mathrm{C}$ & 'Triangle' & KWS & 20 & \\
\hline & $\mathrm{D}$ & 'Nelson' & SYNGENTA & 20 & \\
\hline \multirow{7}{*}{ Harvested varieties } & $\mathrm{E}$ & 'PR46W31' & Kırklareli-Karıncak Köyü & 10 & 229 \\
\hline & $\mathrm{F}$ & 'Licord' (K) & Kırklareli-Kofçaz & 10 & 425 \\
\hline & G & 'Californium' & Edirne-Kapıkule & 10 & 61 \\
\hline & $\mathrm{H}$ & 'Elvis' & Edirne-Süloğlu & 10 & 150 \\
\hline & I & 'Tarcoola' & Tekirdağ-Karaevli & 10 & 140 \\
\hline & $\mathrm{J}$ & 'Licord' (T) & Tekirdağ-Muratlı & 10 & 93 \\
\hline & & & Total: & 140 & \\
\hline
\end{tabular}

KWS, and Syngenta kindly provided the seeds of Triangle and Tristan, and NK Petrol and Nelson respectively in the bulk form.

Tab. 1 shows the altitudes of the locations from where the harvested varieties were collected. Also shown are the names of the collection locations and the companies provided canola seeds and the variety codes that were used in this study. Throughout the text, the different varieties were identified by these codes. Ten genotypes per harvested varieties and 20 genotypes per varieties provided by commercial companies were randomly selected in total 140 genotypes for RAPD analysis.

\section{$D N A$ extraction}

The genomic DNA was extracted as described by Amani et al. (2011) from the leaves of 1-1.5 month old plants, which were grown in the plastic pots.

\section{DNA amplification}

For DNA amplification, RAPD assays were carried out in $20 \mu \mathrm{L}$ reaction mixture containing template $2 \mu \mathrm{L} 10 \mathrm{X}$ Taq buffer (complete), $0.5 \mu \mathrm{L}$ dNTP mixture $(25 \mathrm{mM}$ each), $0.5 \mu \mathrm{L}$ of Taq DNA polymerase $(500 \mathrm{u} / \mu \mathrm{L}$, Bioron),
$0.5 \mu \mathrm{L}$ primer ( $100 \mathrm{pmol}$, Metabion International AG), 5 $\mu \mathrm{L}$ DNA (50-100 ng) and distilled water up to $20 \mu \mathrm{L}$. The amplification was performed in a Thermo Scientific thermocycler PCR system. The DNA amplification was obtained as followed: $94^{\circ} \mathrm{C}$ for $5 \mathrm{~min}, 40$ cycles of $94^{\circ} \mathrm{C}$ for 1 $\min , 33^{\circ} \mathrm{C}$ for $1 \mathrm{~min}$, and $72^{\circ} \mathrm{C}$ for $2 \mathrm{~min}$, followed by one cycle of $72^{\circ} \mathrm{C}$ for $10 \mathrm{~min}$. The amplified DNA products were resolved on $1.3 \%$ agarose gel, visualized by ethidium bromide $(10 \mathrm{mg} / \mu \mathrm{L})$ staining, and photographed with transmitted UV light (DNR bioimaging System). RAPD bands were scored from photographs and gels into a binary data matrix as 1 (present) or 0 (absent).

\section{Estimation of reproducibility rate of $R A P D$ bands}

For estimation of reproducibility rate of RAPD bands, randomly an individual genotype from each harvested variety and two from varieties provided by the commercial companies, in total 14 genotypes were selected and formed a repeat group in this study. Then the same PCR conditions and primers, used in the study were applied for the repeat group to determine the reproducibility rates of the RAPD bands. Finally, the RAPD bands of the repeat group and the first run of the same samples were compared.

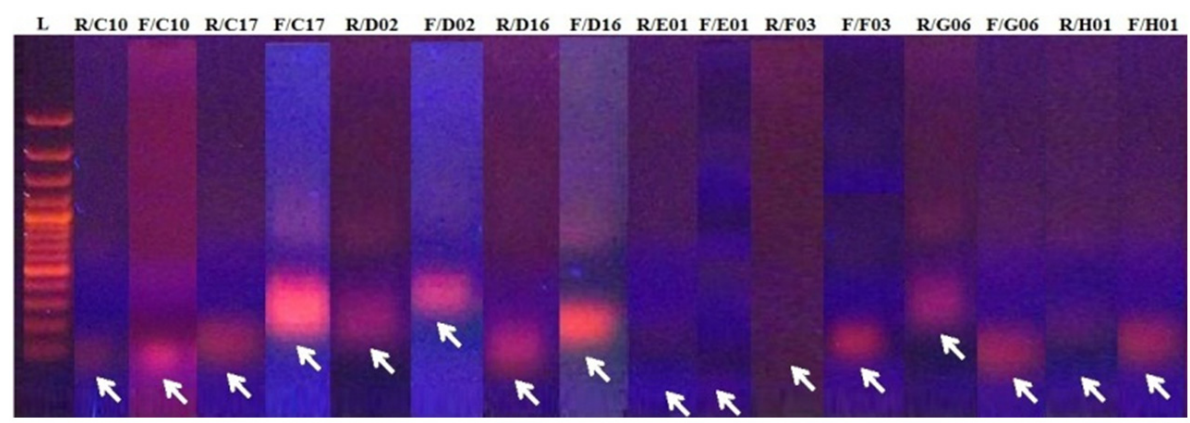

Fig. 1. RAPD-PCR band patterns, which were produced by ABN02 primer, of repeated and first run the same samples. Sample order: Lane 1 molecular weight DNA ladder (100 bp), Lanes 2-5 from variety C, Lanes 6-9 from variety D, Lanes 10-11 from variety E, Lanes 12-13 from variety $F$, Lanes $14-15$ from variety $G$ and Lanes 16-17 from variety $H$ (Abbreviations: DNA Ladder L, first run F and Repeat $\mathrm{R}$ ) 
116

The results were counted as 184 and 188 RAPD bands in the first run and in the run of the repeat group respectively. Among these bands, 154 were repeated and reproducibility of the RAPD bands was $83.16 \%$ in this study (Fig. 1).

\section{Statistical analysis}

The RAPD bands are biallelic and dominant markers. The data considered as diploid and dominant were analysed using POPGENE version 1.32 (Yeh et al., 1997). The genetic diversity $\left(H_{e}\right)$ based on the allele frequencies at the RAPD loci was calculated according to Nei (1973). The mean number of alleles per locus $(n)$ and the mean number of effective alleles per locus $\left(n_{e a}\right)$ were also calculated. The genetic differentiation between varieties was measured by $G_{S T}$. Gene flow $\left(N_{m}\right)$ was calculated from $G_{S T}$ to determine its effect on the gene diversity.

The genetic data of the harvested varieties were correlated with the eco-geographical data to screen the effects of the environmental factors on genetic diversity of varieties by using Pearson's correlation $\left(r_{\mathrm{p}}\right)$, multiple regression (MR) and principal component analyses (PCA). Following genetic indices were computed with geographical $(A L$, $L T$, and $L N)$ and climatic $(R, T, H$, and $\mathrm{W})$ variables: $n, n_{e a}$, and $H_{e}$. MR employed the genetic variables as dependent and the environmental variables as independent. Pearson's correlation and multiple regression analysis were carried out by using SPSS version 11 for Windows.

Principal component analysis (PCA) was performed using the following genetic indices: $n_{a}, n_{e a}$, and $H_{e}$ as well as geographical $(A L, L T$, and $L N)$ and climatic $(R, T$, $H$, and $\mathrm{W}$ ) data as variables according to the Pearson's (one-tailed) correlation matrix using XLSTAT (version 2012). For the principal coordinates analysis (PCoA) the dissimilarity matrix values, which were calculated using binary data matrix with Jaccard coefficient, were used to ordinate 140 genotypes representing nine different varieties of canola (Brassica napus L.) on a scattered plot using XLSTAT (2012, Addinsoft ${ }^{\mathrm{TM}}$ ).

\section{Results and discussion}

In this study, genetic diversity was analysed in the nine different Turkish commercial rapeseeds (Brassica napus L.) varieties by RAPD method using 10 primers (10-mer oligonucleotides), which produced 51 scorable loci, 31 loci of which were polymorphic (60.78\%) and 20 loci $(39.22 \%)$ were monomorphic (Tab. 2). The primers ABN13 and $\mathrm{AB} 02 / 20$ produced the highest number of locus (7), while the primer $\mathrm{ABN} 02$ produced the lowest number of locus (2). The highest number of polymorphic locus (4) was determined in the RAPD products of $\mathrm{AB} 02 / 06, \mathrm{AB} 02 / 10$, and $\mathrm{AB} 02 / 20$ primers, while the lowest polymorphic locus (1) was determined in the RAPD products of ABN02 primer. The molecular weights of RAPD bands ranged between $100 \mathrm{bp}$ and $1200 \mathrm{bp}$. A representative of RAPDPCR band patterns was given in Fig. 2. At variety level, the highest number (37) of polymorphic locus (72.55\%) was observed in variety I, while the lowest number (21) of polymorphic locus (41.18\%) was observed in variety A.

In this study, the RAPD method displayed $83.16 \%$ of reproducibility. This is a considerably high amount of reproducibility beside its advantages of being fast, easy, not expensive, and less labour work requiring properties. RAPD analysis showed that the method was successful to differentiate the genotypes, which were from the different varieties in this study.

\section{Analysis of genetic diversity}

The mean values of the genetic diversity within population $\left(H_{S}\right)$ and total $\left(H_{T}\right)$ were 0.15 and 0.19 respectively (Tab. 3). The mean values of the genetic differentiation $\left(G_{S T}\right)$ and the gene flow $\left(N_{m}\right)$ between the populations were calculated as 0.20 , and 2.10 respectively. The mean number of allele $(n)$ and the mean value of the genetic diversity $\left(H_{e}\right)$ were 2.00 and 0.15 respectively. The genetic distances $(D)$ between nine different varieties of canola (Brassica napus L.) were calculated according to Nei (1973). The highest genetic distance $(D=0.101)$ was cal-

Tab. 2. The primers, used in the study, total number of locus, which produced by each primer, monomorphic, and polymorphic loci, percentage of polymorphic loci and range of molecular weights produced by 10 RAPD primers in nine different commercial rapeseed (Brassica napus L.) varieties and primer sequences (Abbreviations: Number of locus \#L, monomorphic locus M, polymorphic locus $\mathrm{P}$, and percentage of polymorphic locus \% P, fragment size range FSR)

\begin{tabular}{ccccccc}
\hline Primer & $\# \mathrm{~L}$ & $\mathrm{M}$ & $\mathrm{P}$ & $\% \mathrm{P}$ & FSR $(\mathrm{bp})$ & Primer Sequence \\
\hline $\mathrm{ABN02}$ & $\mathbf{2}$ & 1 & $\mathbf{1}$ & 50 & $100 \mathrm{bp}-500 \mathrm{bp}$ & 5- ACCAGGGGCA -3 \\
$\mathrm{ABN06}$ & 6 & 3 & 3 & 50 & $100 \mathrm{bp}-800 \mathrm{bp}$ & 5- GAGACGCACA -3 \\
$\mathrm{ABN13}$ & 7 & 4 & 3 & 42.85 & $100 \mathrm{bp}-1200 \mathrm{bp}$ & 5- AGCGTCACTC -3 \\
$\mathrm{ABN} 18$ & 5 & 3 & 2 & $\mathbf{4 0}$ & $100 \mathrm{bp}-700 \mathrm{bp}$ & 5- GCTGAGGTCA -3 \\
$\mathrm{AB} 2 / 01$ & 3 & 1 & 2 & 66.66 & $100 \mathrm{bp}-700 \mathrm{bp}$ & 5- CCCAAGGTCC -3 \\
$\mathrm{AB} 2 / 05$ & 5 & 2 & 3 & 60 & $100 \mathrm{bp}-700 \mathrm{bp}$ & 5- TCAGGGAGGT -3 \\
$\mathrm{AB} 2 / 09$ & 4 & 1 & 3 & 75 & $100 \mathrm{bp}-700 \mathrm{bp}$ & 5- CTTCACCCGA -3 \\
$\mathrm{AB} 2 / 06$ & 5 & 1 & $\mathbf{4}$ & 80 & $100 \mathrm{bp}-700 \mathrm{bp}$ & 5- AAGACCCATC -3 \\
$\mathrm{AB} 2 / 10$ & 6 & 2 & $\mathbf{4}$ & 66.66 & $100 \mathrm{bp}-1000 \mathrm{bp}$ & 5- CACCAGGTGA -3 \\
$\mathrm{AB} 2 / 20$ & 7 & 3 & $\mathbf{4}$ & 57.14 & $100 \mathrm{bp}-1000 \mathrm{bp}$ & 5- AACGGTGACC -3 \\
\hline
\end{tabular}

*The highlighted numbers represent the highest and the lowest values observed in the study 


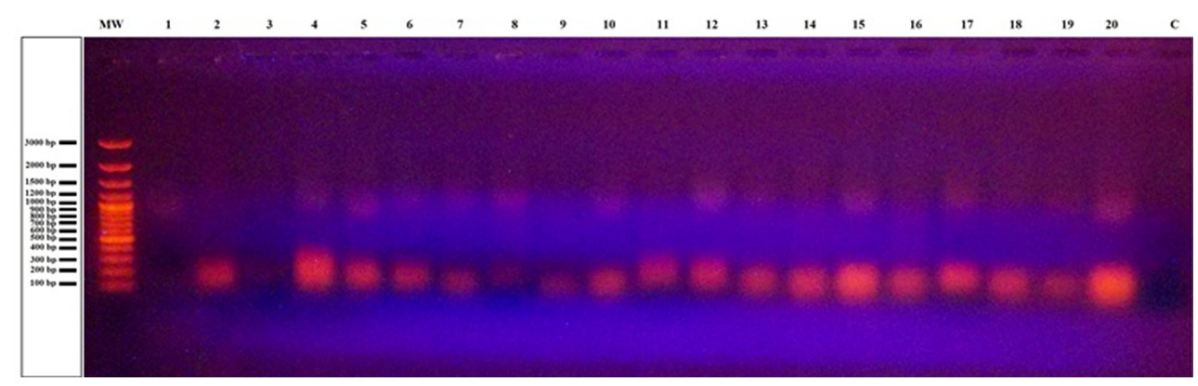

Fig. 2. RAPD band patterns produced by ABN02/09 primer in variety C. Sample order: Lane 1 Molecular weight (MW) DNA ladder (100 bp), Lanes 2-21 samples from population C, Lane 22 negative control (C)

culated between the varieties of $\mathrm{H}$ and $\mathrm{C}$, while the lowest genetic distances $(D=0.010)$ was calculated between the varieties of $\mathrm{H}$ and $\mathrm{G}$.

Genetic diversity estimates were considerably high for B. napus L. as it was observed in previous studies (Fahmi et al., 2012; Fazeli et al., 2008; Hasan et al., 2006; Marjanovic et al., 2009; Moghaddam et al., 2009; Qu et al., 2012). In addition, slightly higher genetic diversity was observed in the harvested varieties than the varieties provided by the commercial companies. A higher-level genetic variation was observed in this study, might be related with hybridization process. In Brassicaceae family, hybridization, introgression and hybrid speciation were reported as significant evolutionary forces. Interspecific gene flow and hybridization contributed to evolution and species diversity of some genera and causes genetic variation (Marhold and Lihova, 2006). The outcrossing mating system, associated with the perennial habit and vegetative reproduction are significant factors for hybridization, constitution, and emplacement of the polyploids (Ančev, 2006).

Molecular tools indicated that other mechanisms are also included in genetic variations; such as: rapid sequence elimination in synthetic hybrids and allopolyploids (Shaked et al., 2001; Song et al., 1995); genomic recombi-

Tab. 3. The alleles $\left(n_{a}\right)$, the effective alleles $\left(n_{a e}\right)$ and the gene diversity $\left(H_{e}\right)$ at variety level for nine different commercial rapeseed (Brassica napus L.) varieties (Abbreviations: Polymorphic locus PL, percentage of polymorphic locus PL (\%)

\begin{tabular}{ccccccc}
\hline Variety & $\mathrm{N}$ & $\mathrm{n}_{a}$ & $\mathrm{n}_{\mathrm{ea}}$ & $\mathrm{H}_{e}$ & $\mathrm{PL}$ & $\mathrm{PL}(\%)$ \\
\hline $\mathrm{A}$ & 20 & $\mathbf{1 . 4 1}$ & 1.20 & $\mathbf{0 . 1 1}$ & $\mathbf{2 1}$ & $\mathbf{4 1 . 1 8}$ \\
$\mathrm{B}$ & 20 & 1.71 & $\mathbf{1 . 2 7}$ & 0.17 & 36 & 70.59 \\
$\mathrm{C}$ & 20 & 1.71 & 1.24 & 0.16 & 36 & 70.59 \\
$\mathrm{D}$ & 20 & 1.45 & $\mathbf{1 . 1 7}$ & $\mathbf{0 . 1 1}$ & 23 & 45.10 \\
$\mathrm{E}$ & 10 & 1.71 & 1.24 & 0.17 & 36 & 70.59 \\
$\mathrm{~F}$ & 10 & 1.69 & 1.19 & 0.14 & 35 & 68.63 \\
$\mathrm{G}$ & 10 & 1.71 & 1.24 & 0.16 & 36 & 70.59 \\
$\mathrm{H}$ & 10 & 1.69 & 1.26 & $\mathbf{0 . 1 8}$ & 35 & 68.63 \\
$\mathrm{I}$ & 10 & $\mathbf{1 . 7 3}$ & 1.24 & 0.17 & $\mathbf{3 7}$ & $\mathbf{7 2 . 5 5}$ \\
$\mathrm{J}$ & 10 & 1.51 & 1.19 & 0.13 & 26 & 50.98 \\
\hline
\end{tabular}

${ }^{*}$ The highlighted numbers represent the highest and the lowest values observed in the study nations in the hybrids; extensive shift in DNA methylation patterns (Liu et al., 2004; Natali et al., 1998; Wang et al., 2005) or activation of mobile genetic elements (transposons and retro transposons; Liu and Wendel, 2000; Shan et al., 2005; Wang et al., 2005) (cited in Tu et al., 2009).

The hybridisation process might also cause to change in the constituent of the canola oil, especially the level of erucic acid. It contains 30-60\% of the total fatty acids of rapeseed, mustard seed, and wallflower seed and it represents up to $80 \%$ of the fatty acids of nasturtium seeds (Food Standards Australia New Zealand, 2000). It was reported that rapeseed oils have toxic effect causing myocarditis in rats due to high level of erucic acid (Roine $e t$ al., 1960). Therefore, the low-level erucic acid trait was transferred in selective breeding programs and agronomically important Brassica napus and Brassica compestris cultivars adapted. The term "canola" is used to refer seeds from the varieties of Brassica napus and Brassica campestris that constitute less than $2 \%$ erucic acid in the oil. These canola varieties comprise almost the entire rapeseed crop produced in the world today (Food Standards Australia New Zealand, 2000).

\section{Pearson's correlation and multiple regression analyses}

According to Pearson's correlation (2-tailed) analyses, wind had negative correlation with the mean number of allele and the mean value of the genetic diversity in the varieties displaying negative correlation; the correlation values were $r_{\mathrm{p}}=-0.883(p=0.020$ at $p<0.05$ significant level) and $r_{\mathrm{p}}=-0.858(p=0.029$ at $p<0.05$ significant level) respectively. The results of MR analysis also showed that wind had effect on the variance of the mean number of allele (88.3\%) and of the mean value of genetic diversity (85.8\%).

The Pearson's correlation analysis indicated that wind had substantial negative effect on the genetic indices of the harvested varieties of $B$. napus L. PCA and MR analyses displayed that eco-geographical factors had substantial effect on genetic indices of harvested varieties of $B$. napus $\mathrm{L}$. Because, extensive breeding programs for some characters might increase their vulnerability to environmental factors, in which they were grown. 
118

\section{Principal component analysis (PCA)}

The PCA (one-tailed) accounted for $96.74 \%$ of the genetic variation based on three components. The first component, which explained $61.09 \%$ of the total variance, was formed by the variables of $n_{a}, n_{c a^{2}}, H, W, H, T, R A$, and $L O$. The second component, representing $19.85 \%$ of the total variance, was formed by the variable $L A$, while the third component, which explained $15.80 \%$ of the total variance, was composed of the variable $A L$.

The mean values of genetic differentiation $\left(G_{S T}\right)$ indicated that $80 \%$ of variation was within varieties and $20 \%$ of variation was between varieties. This amount of genetic differentiation is great amount especially for outcrossing plant species. On the other hand, there is no any knowledge about these varieties, which are the products of a selective breeding program for which characters. These characters might be high yield, biodiesel usage, or for some other characters. RAPD analysis indicated that the genetic distances among the nine Turkish commercial rapeseed varieties studied were very low.

\section{Principal coordinates analyses (PCoA)}

According to the PCoA results, the codes (the letter and the number represent the variety code and genotype number respectively) of the genotypes from each variety were plotted on the two axes of a scattered plot graph (Fig. 3). In the scattered plot graph, the genotypes from the harvested varieties E, F, G, H, I, and J separated clearly from the genotypes representing varieties $\mathrm{A}, \mathrm{B}, \mathrm{C}$ and $\mathrm{D}$ provided by the commercial companies. The genotypes from varieties $A$ and $C$ were grouped together, while the genotypes from variety $B$ separated away from all other varieties. Some of the genotypes (D6, D7, D8, D10, D11, D14, and D20) from variety D were grouped closer to the harvested varieties, while some of the genotypes (D2, D3, D4, D5, D12, D13, D13, D15, D16, D17, D18, and D19) from variety $D$ were grouped with varieties of $A$ and $C$.

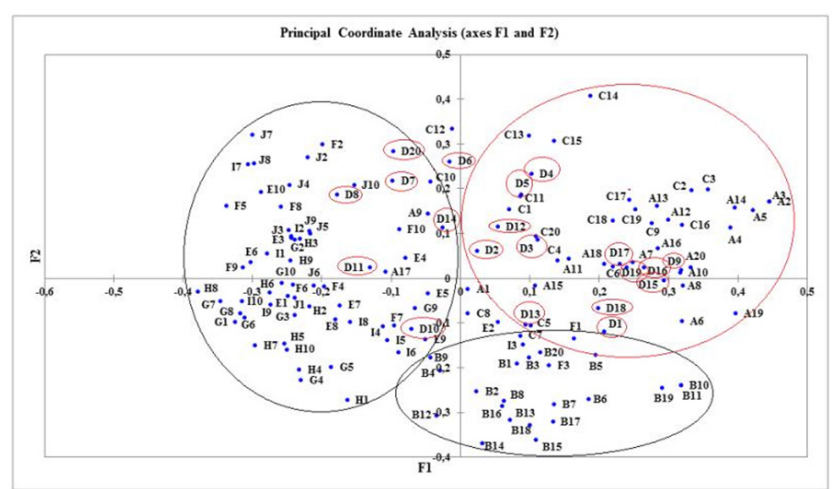

Fig. 3. The scattered ordination plot of the first and second principal coordinates of nine different commercial rapeseed (Brassica napus L.) varieties based on dissimilarity matrix obtained by using 10 RAPD primers
Rapeseeds are important crop plants for food industry, livestock, beekeeping, and biodiesel production etc. They are quite adaptable to the different habitats, except habitats, which have soil with intensive salt stress. It is reported that canola is one of the most profitable crops available to grain growers in southern Australia and rotations have been adapted to accommodate it. Canola increases the yields to benefits of subsequent cereal crops by facilitating an effective disease break. Usually, canola was often planted as the first crop after pasture but now canola is often grown more intensively in rotations, posing problems of herbicide use, disease carryover and increasing potential of blackleg in existing varieties. The sulphur, gypsum, and lime required to grow canola in many regions are beneficial to crops and pastures grown in rotation (Norton et al., 1999). Smith et al. (2008) reported that in their study they rotated canola with field pea, wheat, and flax in different time intervals and determined net canola yield. Canola has high oilseed prices, cereals have low prices, and canola yields are usually $55-60 \%$ of wheat yields when grown under similar situations (Norton et al., 1999). Therefore, canola is the most profitable crop for rotated farming.

\section{Conclusions}

Extensive breeding process is causing to decrease the genetic diversity in germplasm of crop species. Therefore, germplasm of crop species, such as Brassica napus L. should be examined and the genotypes, which have higher genetic diversity index, should be determined and used as potential parental cross material in breeding programs.

\section{Acknowledgement}

This is the Master's Thesis project of Betul Gidik.

\section{References}

Ahmad N, Munir I, Khan IA, Ali W, Muhammad W, Habib R, Khan RS, Swati ZA (2007). PCR-Based Genetic Diversity of Rapeseed germplasm Using RAPD Markers. Biotechnology 6(3):334-338.

Amani J, Kazemi R, Abbasi AR, Salmanian AH (2011). A simple and rapid leaf genomic DNA extraction method for polymerase chain reaction analysis. Iran J Biotechnol 9(1):69-71.

Ančev M (2006) (2006). Polyploidy and hybridization in Bulgarian Brassicaceae: distribution and evolutionary role. Phytol Balcan 12(3):357-366.

Chen S, Zou J, Cowling WA, Meng J (2009). Allelic diversity of a novel Brassica napus gene pool. In: $16^{\text {th }}$ Australian Research Assembly on Brassicas, Ballarat Victoria.

Fahmi AI, Assal OM, Nawar AA, El-Hossary AA, Mohammed MM (2012). Genetic diversity of Brassica napus L. varieties estimated by morphological and molecular markers. Int $\mathrm{J}$ Plant Breed Genet 6(2):83-93. 
Fazeli E, Shahriari F, Samizadeh H, Bagheri A, Farsi M (2008). Evaluation of genetic diversity among different genotypes of Brassica napus using random amplified polymorphic DNA markers. Pak J Bio Sci 11(23):2629-2633.

Food Standards Australia New Zealand (2000). Erucic acid in food: A Toxicological Review and Risk Assessment. Technical Report Series No. 21.

Gečaitė L, Paulauskas A, Jodinskienė M, Radzijevskaja J (2009). Genetic diversity of spring oilseed rape (Brassica napus L.). Acta Biologica Universitatis Daugavpiliensis 9(1):13-18.

Hasan M, Seyis F, Badani AG, Pons-Kühnemann J, Friedt W, Lühs W, Snowdon RJ (2006). Analysis of genetic diversity in the Brassica napus L. gene pool using SSR markers. Genet Resour Crop Evol 53:793-802.

Kimber DS, Mcgregor DI (1995). The species and their origin, cultivation and world production, 1-9 p. In: Kimber D, McGregor DI (Eds.). Brassica Oilseeds: Production and Utilization. CABI Publishing, Wallingford, UK.

Liu B, Wendel JF (2000). Retrotransposon activation followed by rapid repression in introgressed rice plants. Genome 43:874-880.

Liu ZL, Wang YM, Shen Y, Guo WL, Hao S, Liu B (2004). Extensive alterations in DNA methylation and transcription in rice caused by introgression from Zizania latifolia. Plant Mol Bio 54:571-582.

Marhold K, Lihova J (2006). Polyploidy, hybridization and reticulate evolution: lessons from the Brassicaceae K. Plant Syst Evol 259:143-174.

Marjanovic JA, Kondic SA, Saftic PD, Marinkovic R, Hristov N (2009). Phenotypic and molecular evaluation of genetic diversity of rapeseed (Brassica napus L.) genotypes. Afr J Biotechnol 8(19):4835-4844.

Moghaddam M, Mohammmadi SA, Mohebalipour N, Toorchi M, Aharizad S, Javidfar F (2009). Assessment of genetic diversity in rapeseed cultivars as revealed by RAPD and microsatellite markers. Afr J Biotechnol 8(14):3160-3167.

Natali L, Giordani T, Polizzi E, Pugliesi C, Fambrini M, Cavallini A (1998). Genomic alteration in the interspecific hybrid Helianthus annuus $\times$ Helianthus tuberosus. Theor Appl Genet 97:1240-1247.

Nei M (1973). Analysis of gene diversity in subdivided populations (population structure/ genetic variability/ heterozygosity/ gene differentiation). Proc Natl Acad Sci USA $70(12): 3321-3323$.

Nisar A, Iqbal M, Imtiaz AK, Waqar A (2007). PCR- Based genetic diversity of rapeseed germplasm using RAPD markers. Biotechnology 6(3):334-338.

Norton R, Kirkegaard J, Angus J, Potter T (1999). Canola in rotations. In: Poceedings of $10^{\text {th }}$ Rapeseed Congress, Canberra, Australia.
Qu C, Hasan M, Lu K, Liu L, Liu X, Xie J, Wang M, Lu J, Odat N, Wang R, Chen L, Tang Z, Li J (2012). Genetic diversity and relationship analysis of the Brassica napus germplasm using simple sequence repeat (SSR) markers. Afr J Biotechnol 11(27):6923-6933.

Roine T, Uksila E, Teir H, Rapola H (1960). Histopathological changes in rats and pigs fed rapeseed oil. Z Ernaehrungswiss 1:118-124.

Shahid A, Iqbal M, Inamullah MA, Farhatullah Ijaz A, Iqbal A, Mushtaq A, Khan MW, Abbas SJ, Swati ZA (2011). Characterization of Brassica napus germplasm based on molecular markers. Afr J Biotechnol 10(6):3035-3030.

Shaked H, Kashkush K, Ozkan H, Feldman M, Levy AA (2001). Sequence elimination and cytosine methylation are rapid and reproducible responses of the genome to wide hybridization and allopolyploidy in wheat. The Plant Cell 13:1749-1759.

Shan XH, Liu ZL, Dong ZY, Wang YM, Chen Y, Lin XY, Long LK, Han FP, Dong YS, Liu B (2005). Mobilization of the active mite transposons $\mathrm{mPing}$ and Pong in rice by introgression from wild rice (Zizania latifolia Griseb.). Mol Biol Evol 22:976-990.

Shiran B, Azimkhani R, Mohammadi S, Ahmadi MR (2006). Potential Use of Random Amplified Polymorphic DNA Marker in Assessment of Genetic Diversity and Identification of Rapeseed (Brassica napus L.). Cultivars Biotechnol 5(2):153-159.

Smith EG, Favret ML, Brandt SA, Kutcher HR (2008). Research poster. Economics of Shorting Canola Rotations. http://www.bayercropscience.ca/PDF/InVigor/ES08Feb_ poster.pdf

Song K, Lu P, Tang K, Osborn TC (1995). Rapid genome change in synthetic polyploids of Brassica and its implications for polyploidy evolution. Proc Natl Acad Sci USA 92:7719-7723.

Tu Y, Sun J, Ge X, Li Z (2009). Chromosome elimination, addition and introgression in intertribal partial hybrids between Brassica rapa and Isatis indigotica. Ann Bot 103:1039-1048.

Wang YM, Dong ZY, Zhang ZJ (2005). Extensive de novo genomic variation in rice induced by introgression from wild rice (Zizania latifolia Griseb.). Genetics 170:1945-1956.

Wang YM, Dong ZY, Zhang ZJ, Lin XY, Shen Y, Zhou D, Liu B (2005). Extensive de novo genomic variation in rice induced by introgression from wild rice (Zizania latifolia Griseb.). Genetics 170:1945-1956.

Yeh FC, Yang RC, Boyle T, Ye ZH, Mao JX (1997). POPGENE (version 1.32): The 523 user-friendly shareware for population genetic analysis. Molecular Biology and 524 Biotechnology Centre, University of Alberta Canada. 